\title{
Application of Remote Sensing and GIS in Forest Cover Change in Tehsil Barawal, District Dir, Pakistan
}

\author{
Anwar Sajjad 1*, Ahmad Hussain², Umar Wahab1, Syed Adnan³, Saqib Ali", \\ Zahoor Ahmad', Ashfaq Ali 6 \\ ${ }^{1}$ Department of Environmental Sciences, University of Haripur, Haripur, Pakistan \\ ${ }^{2}$ Department of Forestry and Wildlife, University of Haripur, Haripur, Pakistan \\ ${ }^{3}$ Institute of Geographical Information Systems, National University of Sciences and Technology (NUST), \\ Islamabad, Pakistan \\ ${ }^{4}$ Hubei Insect Resources Utilization and Sustainable Pest Management Key Laboratory, College of Plant Science \\ and Technology, Huazhong Agricultural University, Wuhan, China \\ ${ }^{5}$ Department of Plant Pathology, College of Plant Science and Technology and the Key Lab of Crop Disease \\ Monitoring \& Safety Control in Hubei Province, Huazhong Agricultural University, Wuhan, China \\ ${ }^{6}$ College of Horticulture and Forestry Sciences, Huazhong Agriculture University, Wuhan, China \\ Email: anwarsajjad7@gmail.com
}

Received 11 May 2015; accepted 20 June 2015; published 23 June 2015

Copyright (C) 2015 by authors and Scientific Research Publishing Inc.

This work is licensed under the Creative Commons Attribution International License (CC BY).

http://creativecommons.org/licenses/by/4.0/

c) (i) Open Access

\section{Abstract}

The forests of Pakistan replicate plentiful climatic, physiographic and edaphic differences in the country and these forests face a serious problem of deforestation. Geographic information system (GIS) techniques and remote sensing (RS) from satellite platforms offer a best way to identify those areas of deforestation, and thus a GIS and RS based study was conducted in tehsil Barawal, district Dir (U) to analyze forest cover change. The main objectives of the study were to: 1 ) identify different classes of land use and land cover, and its spatial distribution in the study area; 2) determine the trend, nature, location and magnitude of forest cover change; and 3) prepare maps of forest-cover change in different time periods in the study area. To assess the objectives remote sensing and GIS techniques were utilized. A supervised image classification technique was applied on Landsat 5 satellite images of 2000 and 2012. Five main classes such as agriculture, forest, barren land, snow and water were identified. The results showed that the area of forest, barren land, agriculture, water and snow in year 2000 was $49.54 \%, 43.38 \%, 5.19 \%, 1.40 \%$ and $0.49 \%$ and the area in 2012 was $37.17 \%, 41.36 \%, 12.69 \%, 5.05 \%$ and $3.72 \%$ respectively. Furthermore $2.02 \%$ decrease in barren land, $12.37 \%$ decrease in forest and $7.5 \%$ increase in agriculture land were identified. Due to high deforestation rate and increased agricultural activities, it is recommended

*Corresponding author.

How to cite this paper: Sajjad, A., Hussain, A., Wahab, U., Adnan, S., Ali, S., Ahmad, Z. and Ali, A. (2015) Application of Remote Sensing and GIS in Forest Cover Change in Tehsil Barawal, District Dir, Pakistan. American Journal of Plant Sciences, 6, 1501-1508. http://dx.doi.org/10.4236/ajps.2015.69149 
that awareness campaign should be launched in the study area to protect and conserve this forest from further deforestation.

\author{
Keywords
}

Deforestation, Change Analysis, Forest Cover Change

\title{
1. Introduction
}

In Pakistan forest area is only 4.8 million hectare out of its total geographical land [1] [2]. 1.96 million hectare area (43\% of the total forests) is coniferous hill forests; 1.72 million hectare area (37.2\% of the total forests) is scrub or foot hill forests; 0.234 million hectare area is irrigated plantations; 0.297 million hectare area is riverain and 0.35 million hectare area is mangroves in the delta of Indus river [3]. The forest resources of Pakistan are mostly found in the northern parts (15.7\% in Gilgit Baltistan, 6.5\% in Azad Kashmir and 40\% in Khyber Pakhtunkhwa). In Khyber Pakhtunkhwa the forests are mostly spread over the Korakoram, Hindukush and Himalayas mountains and Scrub, and coniferous forests are mostly found in the upper slopes of district Dir, Swat, Mansehra and Chitral while the alpine pastures are found on the ridges of the mountains.

Forest provides goods and services including water, shelter, flood, folder, nutrient cycling, cultural and recreation value. Forest also helps in providing habitat for wildlife and also improves land degradation and desertification [4]. Trees and forest resources in Khyber Pakhtunkhwa have a vital role in the rural livelihood. Most people depend on forest resources and obtain for fodder for maintenances, wood for houses and fuel wood for fire. Additionally local people gather various NTFPs from forests for household use and cash income [5].

Globally six million hectare forest lands are changed due to logging, agricultural, mining and other human activities [6]. According to the United Nations Framework Convention on Climate Change (UNFCCC), the main cause of deforestation was agriculture. $32 \%$ of deforestation is due to commercial agriculture; $48 \%$ of deforestation is due to existed farming; $14 \%$ logging is responsible for deforestation and $5 \%$ of wood collection is responsible of deforestation [7] [8].

The use of GIS and remotely sensed data in mapping different natural resources management and environmental modeling are gaining mass momentum in recent years. Majority of work in remote sensing was mainly focused on environmental studies in the last few decades. The implication of Remote Sensing and Geographic Information System to forest cover change and urban planning is now getting attention and interest among GIS and remote sensing professionals. The techniques are becoming an important part of watershed management, urban planning, hydrological modeling, drought prediction, and forest cover mapping. Remote sensed data provide advantages like synoptic coverage, consistency in data, global reach and readability, precision and maximum accuracy in data provision [9].

Geographical Information System and Remote sensing has been efficiently and widely used much in single thematic analysis such as land use and land cover change mapping [9] [10], forest monitoring [11], watershed management and forest fire management (Kachmar and Sánchez-Azofeifa, 2003), and forest strategy appraisal [12]. Remote sensing studies showed that the rate of deforestation in Khyber Pakhtunkhwa is high and within 30 years forest will completely disappear. Significant progress has been made in tree plantation on farmland but it is unable to compensate the loss of natural forest (Suleri, 2006). Therefore the purpose of the study was to 1) identify different classes of land use and land cover, and its spatial distribution in the study area; 2) determine the trend, nature, location and magnitude of forest cover change; and 3) prepare maps of forest cover change in different time periods in Tehsil Barawal District Dir (Upper).

\section{Materials and Method}

\subsection{Study Area}

Geographically the study area Tesil Barawal is located In District Dir Upper. The area lies between north latitudes $34^{\circ} 37^{\prime}$ and $35^{\circ} 21^{\prime}$ and east longitude $71^{\circ} 30^{\prime}$ and $72^{\circ} 21^{\prime}$. North of the area lies Chitral, Afghanistan on west, Dir upper forest on east in lower Dir Maidan valley in south part of the area [12] [13]. As shown in Figure 1. Total population of the area is 61,674 as per district censes report of upper Dir 1998 (Upper Dir, 1998). The area is 


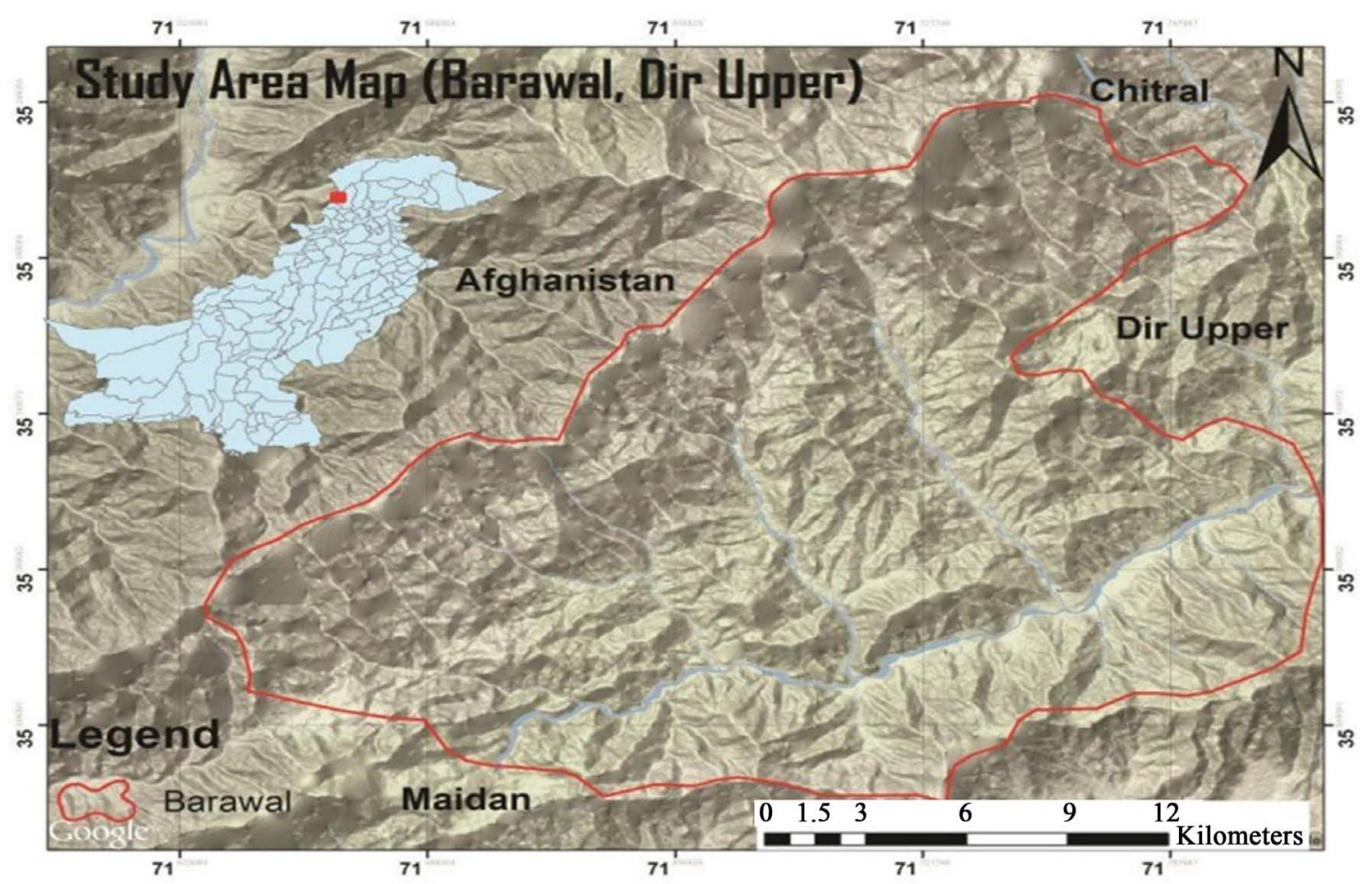

Figure 1. Stud area map (Barawal, Dir Upper).

dominated by different type of forests i.e. spruce (Picea smithiana) and Mixed fir (Abies pindrow) forests, spruce (Picea smithiana), mixed fir (Abies pindrow) and kail (Pinus wallichiana) and broad leaved species forests, Pure kail (Pinus wallichiana) forests and Oak (Quercus species) forest [14] [15].

\subsection{Methodology}

Post-classification technique was carried to analyses the forest cover change in study area. The most commonly method was used to analyze forest cover change dynamics in the study area. It involves classification and rectification each remotely sensed image. After the image classification clearly, compared the resulting maps on a pixel-by-pixel basis using a change detection matrix. The flowing steps were carried out in procedure of image processing: 1) data collection, 2) data preparation, 3) supervised image classification, 4) analysis and 5) preparation of change detection maps. These applications was carried out using ERDAS imagine 9.2 and Arc GIS 10 software.

\subsection{Data Collection}

For change detection over a period of time we required temporal satellite imagery of same time period and same season. Landsat 5 Satellite images of two time periods i.e. 2000 and 2012 were downloaded from United State of Geological Survey website (http://glovis.usgs.gov/).

\subsection{Data Preparation}

Prior step before carrying out analysis is data preparation in which we was refine satellite imagery to carry out detailed study. Forest cover change detection consists of geo referencing and sub-setting of images .Sub setting of an image is done to clip study area from a complete scene.

\subsection{Supervised Image Classification}

Classification is the process of sorting pixels into a finite number of individual classes, or categories of data, based on their data file values. If a pixel satisfies a certain set of criteria, the pixel is assigned to the class that corresponds 
to that criterion. This process is also referred to as image segmentation. It consists of following three steps that were used to classify the images.

\subsection{Pattern Recognition}

Pattern recognition is the science and art of finding meaningful patterns in data, which can be extracted through classification. Pattern recognition can be done with human eye after spatial and spectral enhancement of images.

\subsection{Training Stage}

Analyst is responsible to control supervised training. In training stage researcher pick those pixels that represent a pattern or a land cover structures that he recognizes. Before classification research must have knowledge of the data, and of the desired classes. Once the pattern is identified, analyst can instruct the computer system to recognize pixels with similar characteristics. Accurate classification can result classes that represent the categories within the data that has originally identified in the image. For our research forest cover was divided into different classes or categories such as water, snow, forest, agriculture etc. This stage is further divided into two parts:

- Selection of training sites-by using seed pixel method.

- Selection of feature space for classification-that showed least co variance between two bands.

\section{Signature Evaluation}

Once signatures are created, they were evaluated by using signature alarm utility. It highlights the pixels in the Viewer that belong to, or are estimated to belong to a class according to the parallelepiped decision rule.

\subsection{Classification Stage}

The training result gives a set of signatures that describes a training cluster or sample. Each signature relates to a class is used with a decision rule to assign the same pixels in the image file to a class. When the signatures were created then the pixels of the image were arranged into classes based on the signatures by use of a classification decision rule. Maximum likelihood method was used to classify the pixels. It is a classification system in which unidentified pixels are allocated to classes using outlines of likelihood around training areas using the maximumlikelihood statistic.

\subsection{Analysis}

After all the classification of all maps they was reclassified into desired forest cover classes by using reclassification tool in Arc GIS 10 and then their respective areas were calculated by using raster calculator option. Graphs will also be prepared of all the land cover types for each year.

\section{Results}

\subsection{Image Classification of the Year 2000}

The satellite image of year 2000 was classified into 5 classes (Figure 2). The result showed that the area of forest, agriculture, barren land, snow and water was 19,349, 2028, 16,995, 188 and 549 hectares (Table 1). The Figure 3 showed that the forest areas are mostly concentrated in the South-West and South-East and of the study area while the agriculture is mostly concentrated in the North-West of the study area. Where the North-East parts have low

Table 1. Classification results of the image 2000.

\begin{tabular}{cccc}
\hline S No & Class Name & Area in 2000 (ha) & Percentage \\
1 & Forest & 19,349 & 49.54 \\
2 & Barren & 16,945 & 5.19 \\
3 & Agriculture & 2028 & 1.40 \\
4 & Water & 549 & 0.49 \\
5 & Snow & 188 & 100 \\
\end{tabular}




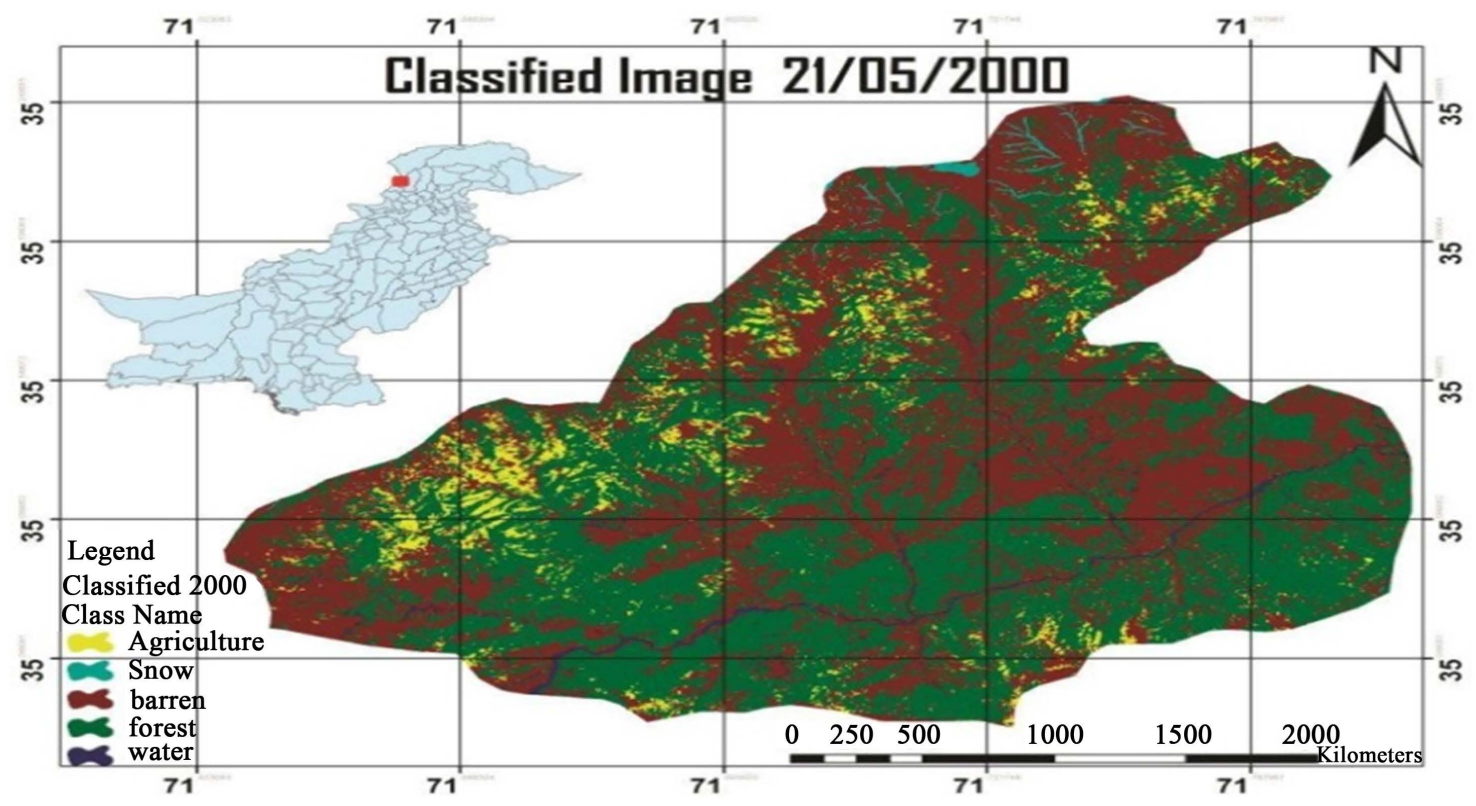

Figure 2. Classified image of the year 2000.

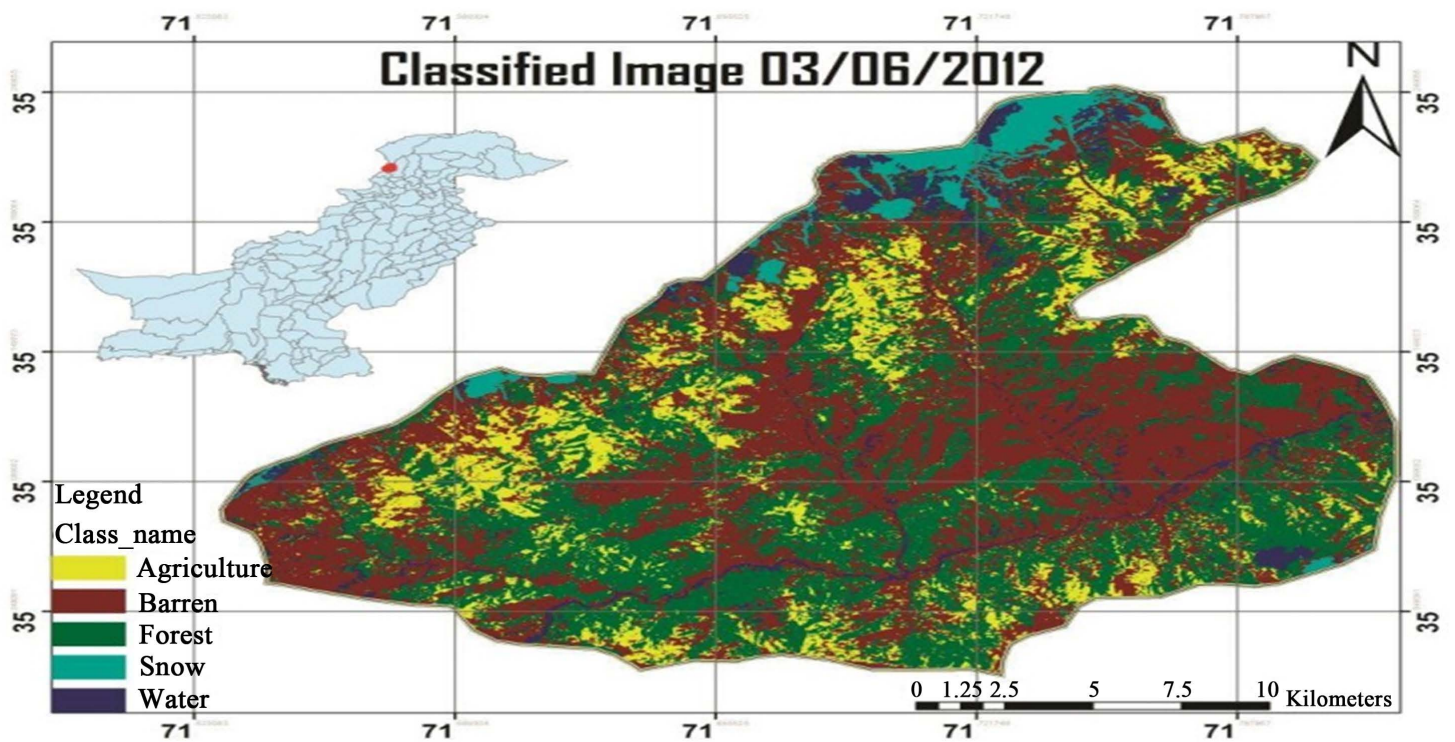

Figure 3. Classified image of the year 2012.

agriculture lands. The barren land is mostly found in the central parts and in the North-East parts. In the northern side peaks of mountains snow was also found.

\subsection{Image Classification of the Year 2012}

The satellite image of year 2012 was classified into 5 classes similar to that of 2000 (Figure 2). The result showed that the area of forest, agriculture, barren land, snow and water was 14,522, 4958, 16,156, 1450 and 1973 hectares (Table 2 and Figure 3).

The Figure 3 showed that the agriculture developments (encroachment) has been started in forest areas which was concentrated in the South-West and South-East parts in 2000, as a result of the which forest area has decreased in such area. Similarly the agriculture lands has been further developed and intensified in the North-West side of Barawal valley while the North-East side has also significant agriculture developments. 
Table 2. Classification results of the image 2012.

\begin{tabular}{cccc}
\hline S. No & Class Name & Area in 2012 (ha) & Percentage \\
\hline 1 & Barren & 16,156 & 41.36 \\
2 & Forest & 14,522 & 37.17 \\
3 & Agriculture & 4958 & 12.69 \\
4 & Water & 1973 & 5.05 \\
5 & Snow & 1450 & 3.72 \\
\hline
\end{tabular}

\subsection{Changes in Land Use and Land Cover from 2000 to 2012}

The Table 3 shows the comparison that how much changes have been occurred from 2000 to 2012 . The results showed that the forest area has been changed/ decreased up to 4826 hectare which makes up about $12.37 \%$ from that of image 2000. Similarly the agriculture area has increased about 2930 hectares which make up about $7.5 \%$ increase.

\subsection{Accuracy Assessment Using Error Matrix for Classified Image of Year 2000 and 2012}

The Error Matrix was calculated to understand the accuracy of classification for the year 2000 and 2012 . The error matrix is calculated pixel by pixel basis. The pixels were converted to percentage thus Table 4 of classified image of the year 2000 showed that only $8.7 \%$ of forest area has been mixed with agriculture land and only $0.4 \%$ of agriculture has been mixed with forest. Similarly Table 5 of classified image of the year 2012 showed that $10.8 \%$ of the forest area has been mixed with agriculture and 3.6\% of agriculture area has been mixed with forest.

\section{Discussion}

\subsection{Land Cover Classification}

In this research we classified two satellite images in to five major classes i.e. agriculture, forest, snow, water and barren land. Main focus was given to forest area because it was our prime objective that how much forest area has changed from 2000 to 2012. A similar study on land use land cover classification is conducted by [16].

\subsection{Forest Cover Change}

To get quantitative information about forest in Barawal Valley from 2000 to 2012, a forest cover change detection was carried out using geographical information system and remote sensing techniques. A post-classification technique as used by (Coppin et al., 2004) was applied for classification and quantitative data analysis on both satellite images of 2000 and 2012.

The classification result of satellite image of year 2000 showed that the percent area of forest, agriculture, barren land, snow and water bodies were 49.54\%, 5.19\%, 43.38\%, 0.49\% and 1.4\% respectively (Table 1 and Figure 2). Similarly the classification result of satellite image of year 2012 showed that the Forest, Agriculture, Barren land was, Snow and Water bodies were 37.17\%, 12.69\%, 41.36\%, 3.73\% and 5.05\% respectively (Table 2 and Figure 3).

From 2000 to 2012 the forest area is decreased by 12\% and agriculture area is increased by $7 \%$. These results are similar to a study conducted on forest cover change assessment in Swat and Shangla which shows that there was about 13\% decrease in forest cover in Swat and 11\% in Shangla [17] [18].

\section{Conclusion and Recommendation}

The classification result of satellite image of year 2000 showed that the percent area of forest, agriculture, barren land, snow and water bodies was 49.54\%, 5.19\%, 43.38\%, 0.49\% and 1.4\% respectively. Similarly the classification result of satellite image of year 2012 showed that the forest, agriculture, barren land, snow and water 
Table 3. Land use land cover changes from 2000 to 2012.

\begin{tabular}{ccccc}
\hline S. No & Class Name & Area in 2012 & Area in 2000 & Change in Area \\
\hline 1 & Agriculture & 12.69 & 5.19 & 7.5 \\
2 & Barren & 41.36 & 43.38 & -2.02 \\
3 & Forest & 37.17 & 49.54 & -12.37 \\
4 & Snow & 3.72 & 0.49 & 3.23 \\
5 & Water & 5.05 & 1.4 & 3.65 \\
\hline
\end{tabular}

Table 4. Error matrix of classified image of year 2000.

\begin{tabular}{cccccccc}
\hline S. No & Classified Data & Agriculture & Snow & Forest & Barren Land & Water & Row Total \\
\hline 1 & Agriculture & 4944 & 0 & 483 & 8 & 0 & 5535 \\
2 & Snow & 0 & 667 & 0 & 0 & 0 & 667 \\
3 & Forest & 186 & 0 & 38,785 & 0 & 0 & 38,971 \\
4 & Barren_Land & 0 & 0 & 77 & 19,202 & 10 & 19,289 \\
5 & Water & 0 & 0 & 24 & 38 & 640 & 702 \\
6 & Column Total & 5130 & 667 & 39,969 & 19,248 & 650 & 65,164 \\
\hline
\end{tabular}

Table 5. Error matrix of classified image of year 2012.

\begin{tabular}{cccccccc}
\hline S. No & Classified Data & Agriculture & Snow & Forest & Barren Land & Water & Row Total \\
\hline 1 & Agriculture & 2774 & 0 & 336 & 0 & 0 & 3110 \\
2 & Snow & 0 & 487 & 0 & 0 & 0 & 487 \\
3 & Forest & 408 & 0 & 10,776 & 0 & 5 & 11,189 \\
4 & Barren_Land & 0 & 0 & 135 & 4482 & 18 & 4635 \\
5 & Water & 0 & 0 & 2 & 0 & 2322 & 2324 \\
6 & Column Total & 3128 & 487 & 11,649 & 4482 & 2345 & 21,745 \\
\hline
\end{tabular}

bodies were 37.17\%, 12.69\%, 41.36\%, 3.73\% and 5.05\% respectively. From 2000 to 2012 the forest area was decreased by $12 \%$ and agriculture area was increased by $7 \%$. Due to high deforestation rate and increased agricultural activities, it is recommended that awareness campaign should be launched in the study area to protect and conserve this forest from further deforestation.

\section{Acknowledgements}

This research was sponsored by the University of Haripur, Khyber Pakhtunkhwa, Pakistan. I am thankfull to Mr. Muhammad Adnan for his technical inputs in completing this research. Thanks are also extended to Ishfaq Ahmad, Rabnawaz Khan, Muhammad Adnan Safi, and Majid Khan reviewing this manuscript.

\section{Conflict of Interest}

The authors have no conflict of interest.

\section{References}

[1] Lubna, H. (2001) Analyzing Institutional Set-Up of Forest Management in Pakistan. Munich Personal RePEc Archive (MPRA) Paper No. 7343, MPRA, Munich. 
[2] Government of Pakistan (2005) Economics Survey. Ministry of Economic Affairs, Government of Pakistan, Islamabad.

[3] Qazi, I.A. (1994) Pakistan: Country and Forests. In: Ashrafm M.M. and Ahmad, I., Eds., Handbook of Forestry, Pakistan Agriculture Research Council, Islamabad, 253.

[4] UNFCCC (2007) Investment and Financial Flows to Address Climate Change. UNFCCC, 81.

[5] Khan, S.R. and Naqvi, A. (2000) The Environment-Poverty Nexus: An Institutional Analysis. Working Paper Series 49, Sustainable Development Policy Institute (SDPI), Islamabad.

[6] Verburg, P.H., Overmars, K.P., Huigen, M.G.A., de Groot, W.T. and Veldkamp, A. (2006) Analysis of the Effects of Land Use Change on Protected Areas in the Philippines. Applied Geography, 26, 153-173. http://dx.doi.org/10.1016/j.apgeog.2005.11.005

[7] Coppin, P., Jonckheere, I., Nackaerts, K., Muys, B. and Lambin, E. (2004) Digital Change Detection Methods in Ecosystem Monitoring: A Review. International Journal of Remote Sensing, 25, 1565-1596. http://dx.doi.org/10.1080/0143116031000101675

[8] Billington, C., Kapos, V., Edwards, M.S., Blyth, S. and Iremonger, S. (1996) Estimated Original Forest Cover Map a First Attempt. WCMC, Cambridge.

[9] Lambing, E.F. (1997) Modeling and Monitoring Land Cover Change Processes in Tropical Regions. Progress in Physical Geography, 2, 375-393. http://dx.doi.org/10.1177/030913339702100303

[10] Rogan, J., Franklin, J. and Roberts, D.A. (2002) A Comparison of Methods for Monitoring Multi-Temporal Vegetation Change Using Thematic Mapper Imagery. Remote Sensing of Environment, 80, 143-156. http://dx.doi.org/10.1016/S0034-4257(01)00296-6

[11] Food and Agriculture Organization, FAO (2000) Forest Resources of Europe, CIS, North America, Australia, Japan and New Zealand. Main Report, ECE/TIM/SP/17, UN, New York and Geneva, 457.

[12] Nagendra, H., Southworth, J., Tucker, C., Karna, B. and Karmacharya, M. (2005) Remote Sensing for Policy Evaluation: Monitoring Parks in Nepal and Honduras. CIPEC, Indiana University, Nepal Forestry Resources and Institutions, Kathmandu.

[13] Abdul, M. (2001) Resource Management Plan for Dir and Samarbagh Forests. Forest Management Centre, N.W.F.P Forest Department, Pakistan.

[14] Ali, J. and Tor, A.B. (2004) Fuel Wood, Timber and Deforestation in the Himalayas: The Case of Basho Valley, Baltistan Region, Pakistan. Mountain Research and Development, 24, 312-318. http://dx.doi.org/10.1659/0276-4741(2004)024[0312:FTADIT]2.0.CO;2

[15] Siddiqui, M.N., Maajid, S., Jamil, Z. and Afser, J. (2006) Integrated Applications of Remote Sensing \& GIS for Mapping \& Monitoring Changes in Forest Cover in Pakistan. Proceedings of the International Seminar on Natural Hazard Monitoring, Karachi, 429-435.

[16] Mya, J. (2010) Analysis of Forest Cover Change Process, Using Remote Sensing and GIS: A Case Study in Sultan Syarif Hasyim Grand Forest Park, Riau Province, Indonesia. Master's Thesis, University of Twente, Enschede.

[17] Shahbaz, B., Ali, T. and Suleri, A.Q. (2006) A Critical Analysis of Policies of Pakistan: Implication for Sustainable Livelihoods. Mitigation and Adaption Strategies of Global Change. Mitigation and Adaptation Strategies for Global Change, 12, 441-453.

[18] World Wide Fund for Nature Pakistan (2009) WWF-Pakistan Forest Cover Change Assessment Using Satellite Images in Swat and Shangla Districts. 